\title{
Why are doctors joining ISIS?
}

$\mathrm{T}$ he militant group, Islamic State of Iraq and Syria (ISIS), is increasing efforts to recruit foreign doctors and medical students.

The push started in the middle of 2015 when ISIS expanded its focus from conquering territory to establishing a religious government, or caliphate, which they claim will unite all Muslims and subjugate the world.

Since June, the group has put out the call for foreign health workers through social media, blogs, splashy magazine spreads and high-budget videos showcasing the state's fledging health system. The propaganda boasts of "extensive" services, state-of-theart facilities and equipment, qualified professionals and two medical schools in which 100 students (half of whom are foreigners) train for free.

At the same time, however, ISIS pleads for more Western doctors to alleviate the suffering of those living under the regime, which one medical recruit attributes to an "overt lack of qualified medical care."

ISIS is particularly desperate for foreign professionals because many locals have fled the group's territory. There are reports of doctors being forced to deliver care at gunpoint and being targeted for arrest, abduction and death. There are stories of soldiers executing doctors who refused to provide care. There are also rumors of organ trafficking and euthanasia. To stem the exodus of health workers, ISIS has threatened to seize the properties of those who don't show up for work and created an office for monitoring their whereabouts.

\section{Not average recruits}

By some estimates, about 30000 foreign recruits poured into Syria last year, doubling the number of volunteers fighting and working for ISIS. A small but alarming number were doctors and medical students from the United Kingdom, Canada and the United States, as well as Australia,

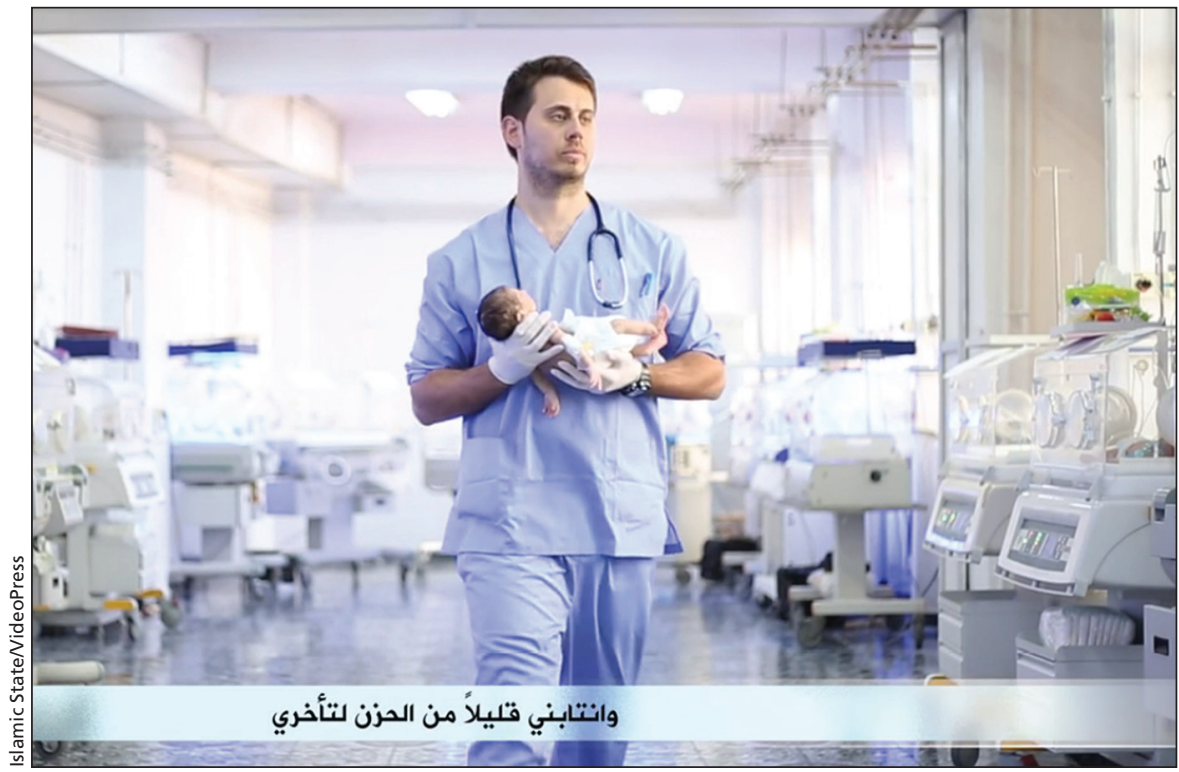

An Australian doctor is among those recruiting other health workers to join Islamic State.

Israel and other wealthy, developed countries.

It's a trend that's hard to track and, for many Westerners, even harder to understand given the media portrayal of jihadists as uneducated, marginalized young people. But the problem is concerning enough that a delegation from the UK recently visited Sudan to dissuade British medical students from following classmates to Syria.

"There is no typical recruit," says Amar Amarasingam, a post-doctoral fellow at the Resilience Research Centre at Dalhousie University in Halifax. "We've seen young and old, men and women, PhDs and high school dropouts, single people and whole families making the journey."

From interviews with foreign recruits and their families, Amarasingam estimates that as many as 100 people have left Canada to join ISIS and about 20 have been killed. "I still hear rumours of Canadians being killed who I had no idea about, so likely there are more."

Michael Zekulin, a University of Calgary anti-terrorism expert, says that reported cases are likely just the "tip of the iceberg."
"For every person who makes the news or who is active on Twitter and Facebook, there are probably equal numbers who are happy to fly under the radar," he says.

\section{Why are they joining?}

The reasons health workers are joining ISIS are as varied as the recruits themselves. "It's a storm of factors, from a quest for significance and identity, to maybe some experience of discrimination," says Lorne Dawson, codirector of the Canadian Network for Research on Terrorism, Security and Society.

What separates ISIS from other extremist groups like Al Qaeda, which attract fewer doctors, is the immediate promise of a "pure" life under a resurrected caliphate, says Dawson. It's a religious ideal that's part of even mainstream Muslim traditions, and one that's "galvanizing" among more conservative sects.

Amarasingam notes that education and privilege aren't an inoculation against this ideal. Recruits "see Western life and morality as bankrupt, and sometimes that becomes clearer the more educated you become." 
This may be why they accept the violence perpetrated by ISIS, explains Dawson. "You can become convinced that some uprising is necessary to complete the purification of the world."

According to Zekulin, some recruits may not "subscribe to the ideology but still identify with the goal of establishing a caliphate as a place where Muslims can be safe." In the early days of the conflict, some may have joined ISIS for purely humanitarian reasons, although Zekulin says that's almost impossible to do now.

More often, social justice concerns are part of what makes a person susceptible to ISIS' call. "A high percentage of doctors are driven by altruism and a desire to help others, and the radical message exploits these motives," says Dawson. "People find it amazing that a doctor would want to be part of this ultraviolent group committing atrocities, but on the flipside a lot of what ISIS does looks like humanitarian, social welfare and medical work."

Of the dozens of videos, thousands of documents and hundreds of thousands of social media messages ISIS puts out each month, "only about $10 \%$ has to do with violence and fighting," Dawson notes. "The vast majority is about how important and good it is to live under the caliphate, as well as charitable and infrastructure programs, including medical facilities."

Experiences of discrimination can also play into the jihadist pitch, says Amarasingam. He cites the case of a Montreal woman who joined ISIS believing she that would have more opportunity as a doctor in Syria than as a visible Muslim in Quebec.

An American survey of Muslim physicians showed that $24 \%$ frequently experienced religious discrimination in their careers and 14\% were currently experiencing religious discrimination at work.

Even the secular culture of medicine can be alienating, says Amarasingam. "My wife is a pediatrician and going to gatherings there's drinking and free mixing of men and women, which conservative Muslims will say is not what they signed up for."

Whatever factors draw health workers to ISIS, they appear to undergo the same process of radicalization as would-be fighters and other recruits, he says. It may start with a friendship, often formed online. "You can quickly be in direct communication through social media, creating deep and personal bonds with these fighters thousands of miles away."

Online networks also provide a link to local recruiters. In Canada, there are rumors of active recruiters in Calgary and Ottawa. "Very few people have just got up and left by themselves. They're always part of these networks," Amarasingam explains.

The groups are usually disconnected from local mosques, he adds. "One of the first things they do is form private study groups creating an echo chamber for themselves."

\section{No easy solutions}

Top-down efforts to identify radicalization often backfire, notes Amarasin- gam. The UK's Prevent program, which requires teachers, health workers and other public authorities to report people who might be vulnerable to extremism, has been criticized for demonizing Muslims and creating a climate of suspicion.

"Growing a long beard, dropping certain friends or dressing differently may simply be signs that a person is becoming a conservative Muslim," Amarasingam says. "All of a sudden law enforcement steps in and it alienates the broader community."

Grassroots initiatives to foster community and religious tolerance may be more effective, just as after-school basketball programs in Somali communities in Toronto have successfully kept teens out of gangs, he explains.

Adapting such programs for older professionals may not be possible or effective, though. In medical institutions, the concept of "vigilance" might be more appropriate, says Dawson. "The analogy I use is suicide. Because we've educated ourselves, when someone threatens to end their life you take it seriously, you talk to them about it and you get help."

Like suicide, "people will start talking about [radical beliefs and acts] long before they do anything," Dawson adds. According to one study, $58 \%$ of people who committed lone acts of terrorism had told someone about their plans prior to the event. "We've got to become attuned to that and stop being idle bystanders." Lauren Vogel, CMAJ

CMAJ 2016. DOI:10.1503/cmaj.109-5217

\section{Prisons face hep C-treatment funding crisis}

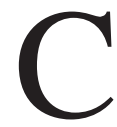

orrectional Service of Canada (CSC) could face a funding shortfall of up to $\$ 100$ million if it adheres to a new standard of care that would see federal inmates infected with hepatitis $\mathrm{C}$ prescribed a new and expensive drug.

Internal government reports, released to CMAJ under the federal access to information law and reviewed by four external experts, appear to indicate that CSC may be delaying treatment for as many as 1750 infected federal inmates. CSC recently released the heavily censored reports to CMAJ, almost ten months past the deadline stipulated under the federal information law.

The funding shortfall is underpinned both by CSC's standard-of- care requirement to use the costly new drugs and a dramatic expansion in the number of inmates potentially treatable with these new drugs, which are better tolerated and more efficacious than the drugs CSC previously used.

In 2014, CSC spent \$4 million to treat about 240 patients with older and cheaper drugs. The new medication will more than triple treatment the cost 